\title{
Tropical SST and Sahel rainfall: A non-stationary relationship
}

\author{
T. Losada, ${ }^{1,2}$ B. Rodriguez-Fonseca, ${ }^{2,3}$ E. Mohino, ${ }^{2}$ J. Bader, ${ }^{4,5}$ S. Janicot, ${ }^{6}$ \\ and C. R. Mechoso ${ }^{7}$ \\ Received 22 May 2012; accepted 6 June 2012; published 30 June 2012.
}

[1] Sea surface temperature (SST) anomalies in the tropical Atlantic have been associated with precipitation anomalies in West Africa that form a dipole pattern with centers over the Sahel and the Gulf of Guinea. Whilst this was clear before the 1970's, the dipole pattern almost disappeared after that date, as the anti-correlation between rainfall anomalies in the Sahel and Guinea dropped abruptly. Simultaneously, the anti-correlations between Sahel rainfall and tropical Pacific SSTs strengthened. It has been posited that these changes after the 1970's developed as rainfall over West Africa started to co-vary with SSTs in the global tropics. In this covariability, enhanced summer rainfall over West Africa with a monopole pattern corresponds to warmer SSTs in the tropical Atlantic and Maritime Continent, and colder SSTs in the tropical Pacific and western Indian Oceans. The present paper describes the hitherto unexplored seasonal evolution of this co-variability and the physical mechanisms at work. Sensitivity experiments with two atmospheric general circulation models demonstrate that, after the 1970's, the impacts of SST anomalies in the Indo-Pacific counteract those in the Atlantic in terms of generating rainfall anomalies over the Sahel, and that this superposition of effects is primarily linear. Therefore, at interannual timescales, the change in the patterns of co-variability between West African rainfall and tropical SSTs can explain the nonstationary relationship between the anomalies in these two fields. Citation: Losada, T., B. Rodriguez-Fonseca, E. Mohino, J. Bader, S. Janicot, and C. R. Mechoso (2012), Tropical SST and Sahel rainfall: A non-stationary relationship, Geophys. Res. Lett., 39, L12705, doi:10.1029/2012GL052423.

\section{Introduction}

[2] The sea surface temperature (SST) anomaly field in the tropics has been recognized as a key driver of rainfall variability in the Sahel during the 20th century. At interannual

\footnotetext{
${ }^{1}$ Instituto de Ciencias Ambientales, Universidad de Castilla-La Mancha, Toledo, Spain.

${ }^{2}$ Departamento de Física de la Tierra, Astronomía y Astrofísica I, Geofísica y Meteorología, Universidad Complutense Madrid, Madrid, Spain.

${ }^{3}$ Instituto de Geociencias, Universidad Complutense Madrid, CSIC, Madrid, Spain.

${ }^{4}$ Max-Planck-Institut fuer Meteorologie, Hamburg, Germany.

${ }^{5}$ Bjerknes Centre for Climate Research, Bergen, Norway.

${ }^{6}$ LOCEAN, IPSL, IRD, Université Pierre et Marie Curie, Paris, France.

${ }^{7}$ Department of Atmospheric Sciences, University of California, Los Angeles, California, USA.

Corresponding author: T. Losada, Instituto de Ciencias Ambientales, Universidad de Castilla-La Mancha, E-45071 Toledo, Spain. (teresa.losada@uclm.es)

C 2012. American Geophysical Union. All Rights Reserved. 0094-8276/12/2012GL052423
}

time scales, SST anomalies in the tropical Atlantic have been associated to precipitation anomalies in West Africa (WA) that form a dipole pattern with centers over the Sahel and the Gulf of Guinea [Rowell et al., 1995; Ward, 1998; Janicot et al., 1998; Losada et al., 2010a]. In addition, a negative correlation was reported between SST anomalies in the tropical Pacific and rainfall anomalies in the Sahel during the northern summer [Folland et al., 1986; Rowell et al., 1995; Ward, 1998; Janicot et al., 1998, 2001; Giannini et al., 2003; Mohino et al., 2011a].

[3] A change in correlations between tropical Atlantic SST and WA rainfall anomalies was found after the 1970's [Janicot et al., 2001; Joly and Voldoire, 2010; RodríguezFonseca et al., 2011; Mohino et al., 2011b, hereinafter MO11]. In this period, the pattern of WA rainfall anomalies associated with the Atlantic Niño changed from a dipoletype with positive values in the Gulf of Guinea and negative values over the Sahel to a monopole-type, with positive values extending north from the Gulf of Guinea.

[4] MO11 examined the co-variability between SST anomalies in each of the tropical ocean basins and rainfall anomalies in WA during the northern summer. They used observations and the outputs of ensemble simulations by five atmospheric general circulation models (AGCMs) in which observed, global SSTs were used as boundary conditions. This was done in a linear context by application of an Extended Maximum Covariance Analysis (EMCA) [Polo et al., 2008], in which the periods 1957-1978 and 19791998 (Periods I and II, respectively) were considered separately. In Period I the patterns of co-variability between WA rainfall and SST anomalies in each of the tropical ocean basins have insignificant projections outside the basin considered. By contrast, in Period II those patterns have significant values in all the basins, with a similar spatial configuration comprising an El Niño-like pattern in the Atlantic together with La Niña-like conditions in the tropical Pacific (Figures A1 and A2 in Text S1 in the auxiliary material). ${ }^{1}$ Rodríguez-Fonseca et al. [2011] obtained a similar result when they applied the EMCA analysis to anomalies in the tropical SSTs and WA rainfall from the observation during the period June-September in Period I and Period II, separately. In view of these findings, MO11 and Rodriguez-Fonseca et al. [2011] conjectured that the reported non-stationary character of the links between tropical SST and WA rainfall at interannual timescales could be due to the different ways in which the impacts of SST anomalies in different ocean basins interfere with each other before and after the 1970's.

[5] The present paper demonstrates the validity of that conjecture in the context of AGCMs. We focus on the period

\footnotetext{
${ }^{1}$ Auxiliary materials are available in the HTML. doi:10.1029/ 2012GL052423.
} 
a)

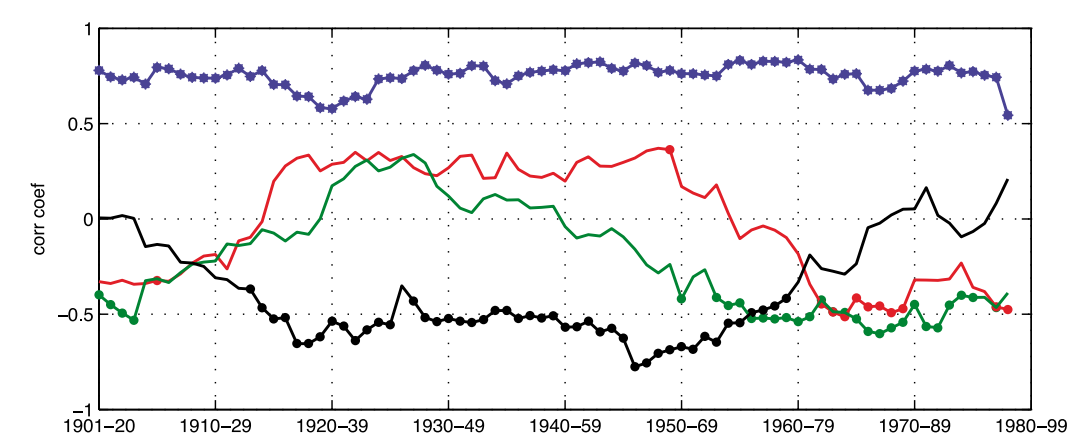

b)
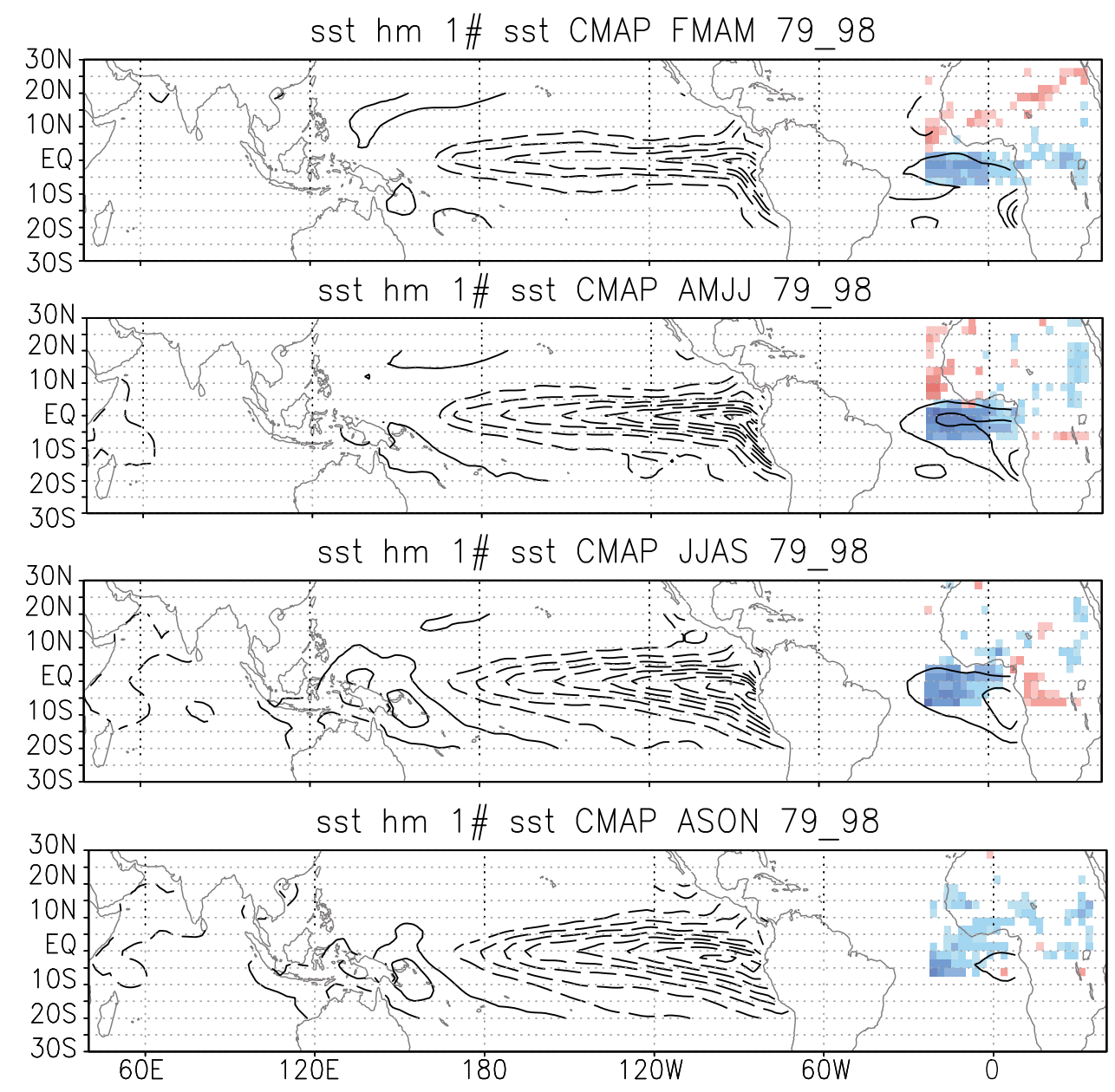

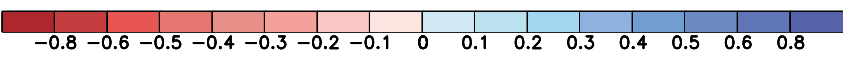
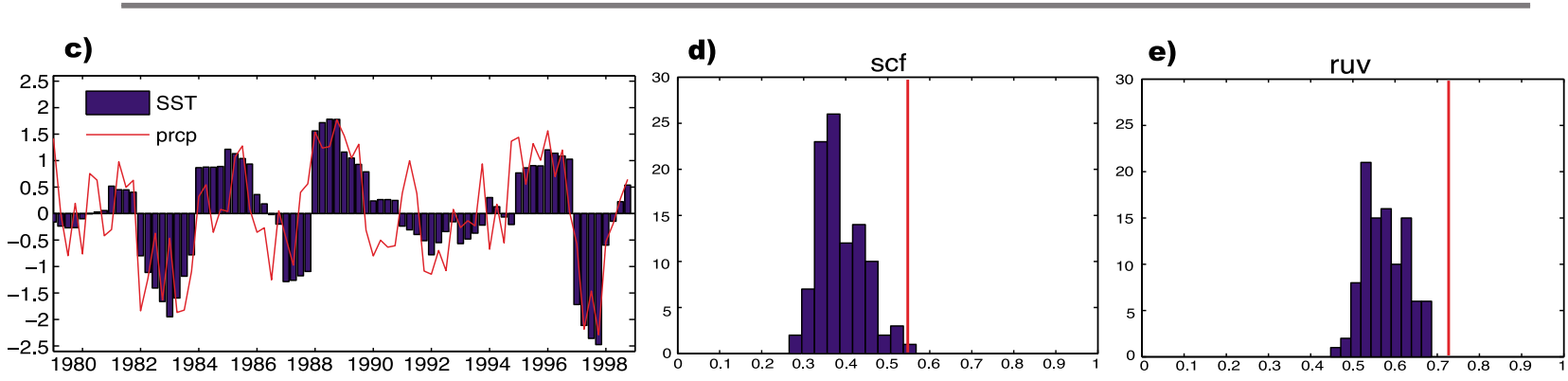

Figure 1 
after the 1970's and start by applying the EMCA analysis to the SST anomalies over global tropics and WA rainfall in order to show the seasonal evolution of the global SST pattern identified by Rodríguez-Fonseca et al. [2011]. Next, we demonstrate, based on ensemble integrations with two AGCMs, that during the selected period the impact of interannual SST anomalies on WA is stationary when the tropical basins are considered separately, and that the linear superposition of the impacts of individual basins qualitatively approximates the global impact when the tropical basins are considered together. Previous papers have addressed the influence of global SST anomalies on WA precipitation [Trzaska et al., 1996; Fontaine et al., 1998; Janicot et al., 2001], but their focus was on the superposition of SST variability in interannual and decadal time scales.

\section{Models, Data, and Methodology}

[6] We use two AGCMs: UCLA v.7.3 [Mechoso et al., 2000; Richter et al., 2008] and LMDZ v.4 [Hourdin et al., 2006]. The model resolutions are, respectively, (2.5 long., $2^{\circ}$ lat., 29 levels), and approximately $\left(3.75^{\circ}\right.$ long., $2.5^{\circ}$ lat, 19 sigma levels). Losada et al. [2010a] and MO11 validated the simulations of the West African Monsoon by these AGCMs, showing that both succeed in reproducing the main temporal and spatial features of the local rainy season. Also, correlations between simulated and observed interannual variability of rainfall in the Sahel and Gulf of Guinea by the two models are positive and significant.

[7] The SST anomalies used in the monthly-mean boundary conditions for the AGCM experiments are obtained from an EMCA analysis applied to the anomalies in SST (ERSST.v2 dataset [Smith and Reynolds, 2004]) over the global tropics (between $180^{\circ} \mathrm{W}-180^{\circ} \mathrm{E}, 20^{\circ} \mathrm{S}-20^{\circ} \mathrm{N}$ ), and rainfall (CMAP dataset [Xie and Arkin, 1997]) over WA (between $21.25^{\circ} \mathrm{W}-33.75^{\circ} \mathrm{E}, 6.25^{\circ} \mathrm{S}-31.25^{\circ} \mathrm{N}$ ). The EMCA is an extension of the Maximum Covariance Analysis [Bretherton et al., 1992] that considers more than one time lag in the predictor array; further description on this methodology is given in Polo et al. [2008]. In our case, the whole evolution of the tropical SST from FMAM (February to May) to SOND (September to December) seasons is considered in relation to JJAS (June to September) WA precipitation. Our choice of the region of precipitation is consistent with MO11 and Rodríguez-Fonseca et al. [2011]. To verify the sensitivity of the EMCA analysis to the choice of region of precipitation, we applied the analysis to a smaller geographical domain between $20^{\circ} \mathrm{W}-15^{\circ} \mathrm{E}, 0^{\circ} \mathrm{E}-20^{\circ} \mathrm{N}$. The results obtained with the larger and smaller regions are highly consistent with each other, both spatially and temporally (not shown). This consistency reflects the importance of the West African
Monsoon on the precipitation distribution over Northern Africa during the warm season.

[8] Based on these results, we select the years in which the absolute value of the JJAS SST Expansion Coefficient is larger than one standard deviation in at least 2 out of the 4 months, and the JJAS precipitation Expansion Coefficient has the same sign as that of the SST for at least 3 of those months. This gives three years with negative expansion coefficients (1982, 1983, 1997 or "negative years") and four years with positive expansion coefficients (1985, 1988, 1989, and 1996 or "positive years"). The SST anomalies for the AGCM experiments are defined as the difference between the fields for the positive and negative years (Figure A4 in Text S1).

[9] We perform three AGCM experiments in which the SST anomalies are either added to the mean SST values for the period 1979-2005 in a selected basin or in the global tropics: 1) "GT", in which the SST anomalies are those from the whole tropical region; 2) "TA", in which only the SST anomalies in the Tropical Atlantic are retained, and 3) "IP", in which only the SST anomalies in the Indian and Pacific Oceans are retained. The Indian and Pacific Ocean are taken together because application of EMCA to Indian Ocean SST and WA rainfall produced non-significant results (MO11). In addition, although the Indian Ocean has its own variability, the variability of the SSTs over the Maritime Continent is highly coupled to that in the Pacific. To avoid discontinuities in the AGCM SST field at $20^{\circ} \mathrm{N}$ and $20^{\circ} \mathrm{S}$, the anomalies added decrease linearly in the 10 degree bands polewards from those latitudes.

[10] All AGCM experiments consist of seven-month long (March through September), 10-member ensemble integrations, in which ensemble members differ in a slight perturbation of the initial conditions. The control simulation is a 10-member ensemble integration with climatological, monthly-mean varying SST corresponding to the 1979-2005 period. To evaluate the atmospheric response to the anomalous SSTs, we calculate the difference between the mean of the sensitivity experiments from the two models and the control simulation. Following Meehl et al. [2007], we use the ratio of mean to standard deviation of each of the models as a measure of the confidence of the results; when this ratio is larger than one the signal is considered to be larger than the noise.

\section{Results}

[11] We start by illustrating the non-stationary relationship between tropical SST and WA rainfall. Figure 1a shows the 20-year moving correlations between the ATL3 (SST anomaly in the region $3^{\circ} \mathrm{S}-3^{\circ} \mathrm{N} ; 20^{\circ} \mathrm{W}-0^{\circ} \mathrm{E}$ ) and Niño3

\footnotetext{
Figure 1. (a) Twenty-year running correlation from 1901-1920 to 1980-99, between observed JJAS Atl3 index and JJAS GG precipitation index (blue line), JJAS Atl3 index and Sahel rainfall index (black line), JJAS Niño3 index and JJAS GG rainfall index (red line) and JJAS Niño3 index and Sahel rainfall index (green line). Dots denote 90\% significant correlations under a Monte Carlo test with 500 realizations. (b) Leading EMCA mode of variability between the FMAM to SOND SST anomalies in the global tropics and JJAS WA precipitation, for Period II. Homogeneous regression map for the SST (contour interval is $0.15^{\circ} \mathrm{C}$; solid (dashed) lines denote positive (negative) SST anomalies) and heterogeneous regression map, lagged over different time-sequences of the anomalous rainfall (shaded). Only those areas with 95\% significant regressions evaluated with a T-test are shown. (c) Expansion coefficients of SST (bars) and precipitation (red line) for the leading EMCA mode. (d) Probability distribution function of scf scores derived from a Monte Carlo test with 100 realizations, represented together with the non-shuffled EMCA score (red line). (e) Same Figure 1d, except for ruv score.
} 

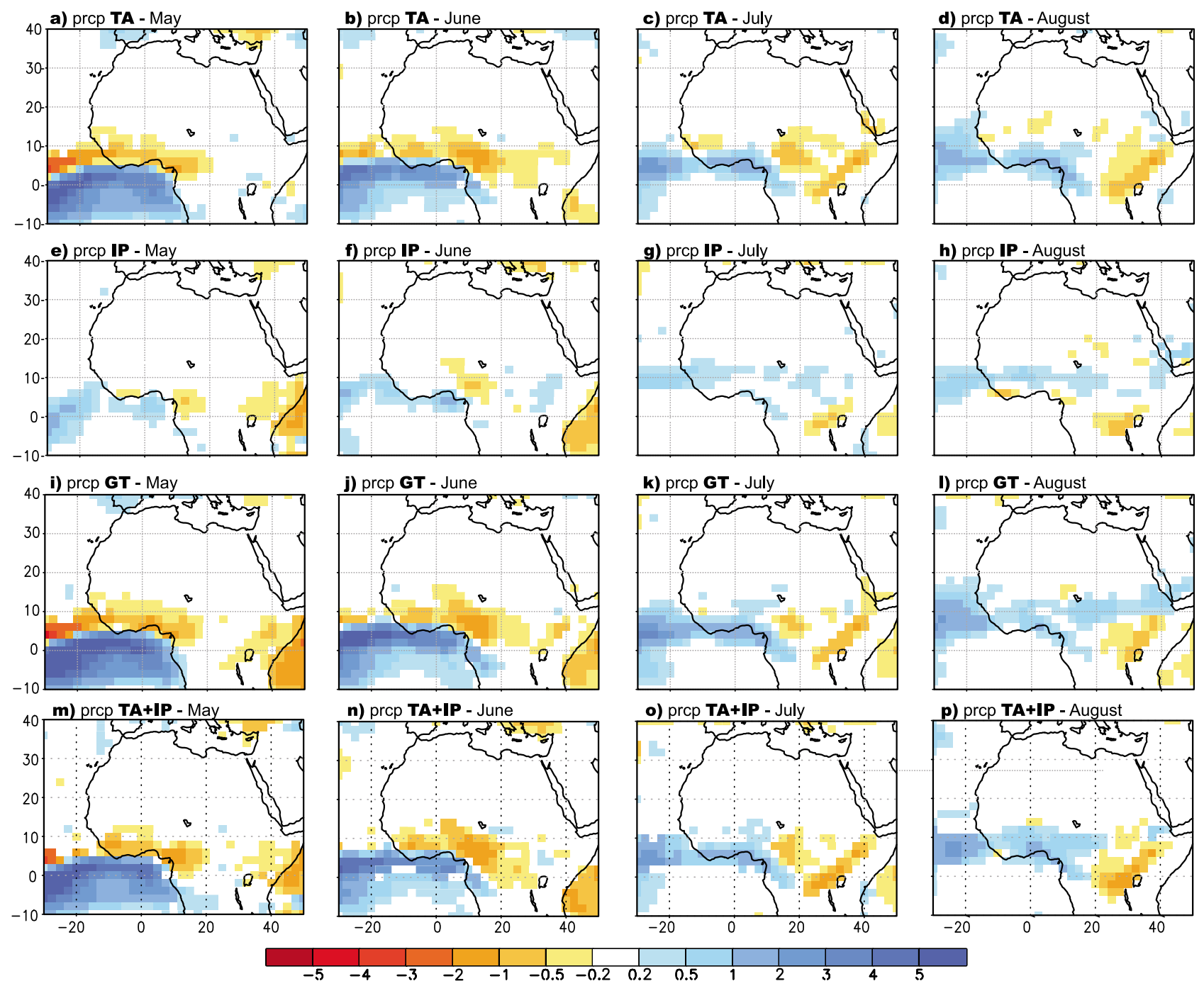

Figure 2. May to August monthly-mean anomalies of precipitation (mm/day) for (a-d) TA; (e-h) IP and; (i-l) GT experiments; and (m-p) sum of TA and IP. Only the regions where the ratio of mean to standard deviation of the models is larger than one are showed.

(SST anomaly in the region $5^{\circ} \mathrm{S}-5^{\circ} \mathrm{N}, 150^{\circ} \mathrm{W}-90^{\circ} \mathrm{W}$ ) indices with the precipitation in the Gulf of Guinea (GG, precipitation anomaly in the region $4^{\circ} \mathrm{N}-8^{\circ} \mathrm{N}, 20^{\circ} \mathrm{W}-10^{\circ} \mathrm{E}$ ) and in the Sahel (precipitation anomaly in the region $10^{\circ} \mathrm{N}-20^{\circ} \mathrm{N}$, $20^{\circ} \mathrm{W}-10^{\circ} \mathrm{E}$ ) in summer. Only the correlation between GG and ATL3 is stationary in time. Sahel precipitation and ATL3 are significantly anticorrelated only during the period between 1920-1970, when the dipole of anomalous rainfall appears. Conversely, correlations between Niño3 and GG and Sahel rainfall are significant only for the pre-1920's and post-1970's. The changes after the 1970's have taken place at about the same time as SST anomalies in the tropical Atlantic and Pacific oceans became significantly anti-correlated at interannual timescales [Polo et al., 2008; RodríguezFonseca et al., 2009].

[12] Next, we describe the seasonal evolution of the leading mode of co-variability from the EMCA analysis described in section 1 (see Figure 1b). For negative lags, the pattern of precipitation anomalies has a dipolar structure, with positive values over the Gulf of Guinea for warm Atlantic (cold Pacific) SST. From July-September onwards, the structure is one-signed over the WA. Regarding the SST pattern, maximum loadings are over the eastern equatorial Pacific basin and the southeastern tropical Atlantic. The signal over the Atlantic evolves from the Angola-Benguela upwelling region (in February-May) towards the Equator. From June-September the Atlantic SST anomalies decay. Over the tropical Pacific, an ENSO-like pattern with anomalies of opposite sign than those of the tropical Atlantic is apparent during the whole time sequence. As the season advances, the maximum loadings over the eastern Pacific extend and cover a wider latitudinal band, while the anomalies over the Maritime Continent become more important. Also, some substantial values appear over the western Indian Ocean, with the same sign of those in the eastern Pacific. It accounts for $54 \%$ of the squared covariance fraction (scf) (Figure 1d); the correlation between expansion coefficients of SST and precipitation (ruv) anomalies is similarly very high (73\%, Figure $1 \mathrm{e})$. Both scf and ruv are significant at $95 \%$ level, with a Montecarlo test of 100 realizations. The non-stationarity of this mode is illustrated in Figure A3 in Text S1 (auxiliary material).

[13] Finally, we examine the impacts of such a Global Tropical SST pattern on WA rainfall by performing the 

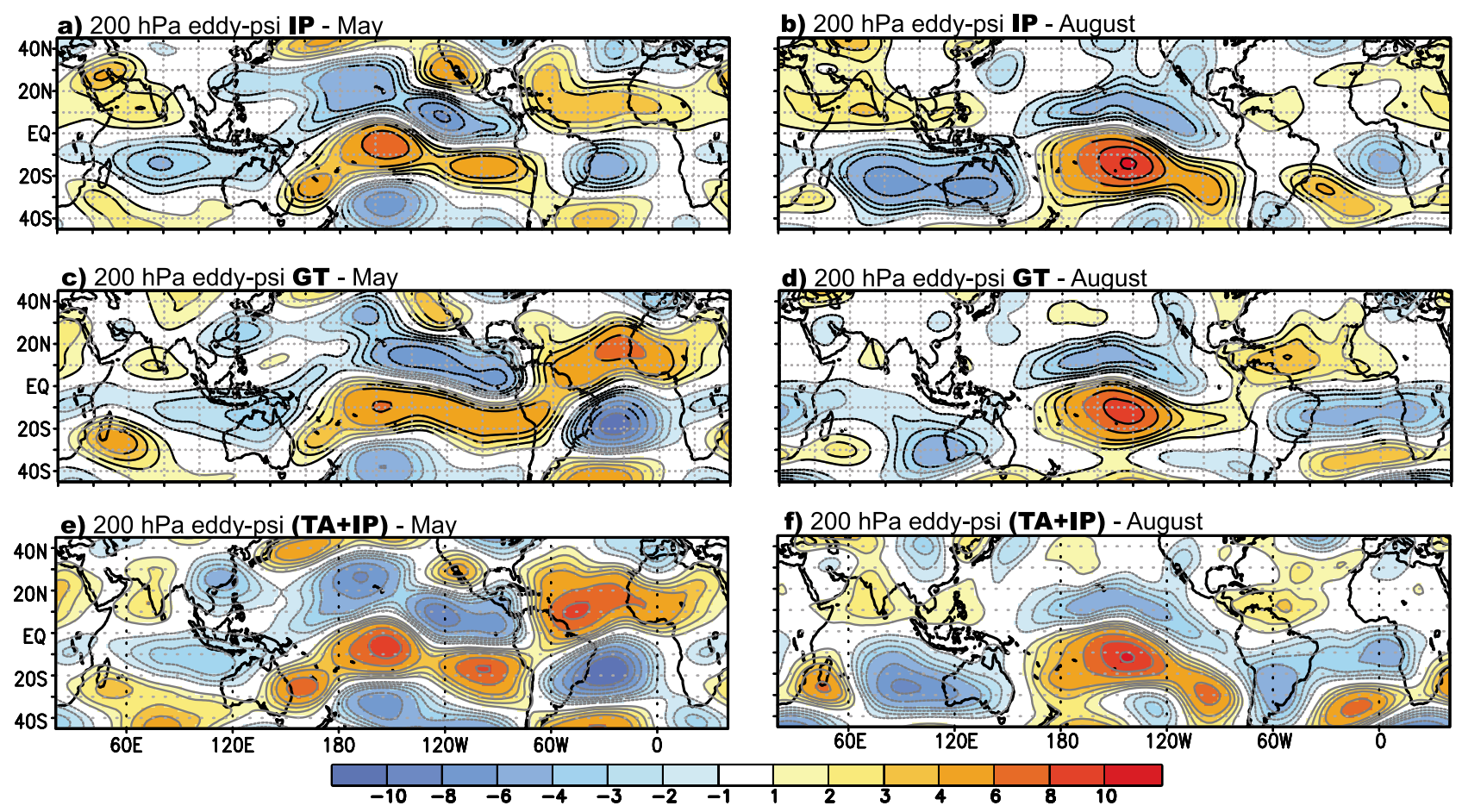

Figure 3. (a, b) May and August $200 \mathrm{hPa}$ eddy-streamfunction monthly-mean anomalies $\left(10^{6} \mathrm{~m}^{2} \mathrm{~s}^{-1}\right)$ for IP experiment. Black contours denote the regions where the ratio mean-standard deviation of both models is larger than one. (c, d) Same as Figures $3 \mathrm{a}$ and $3 \mathrm{~b}$ but for GT experiment. (e, f) Same as Figures $3 \mathrm{a}$ and $3 \mathrm{~b}$ but for the sum of TA and IP experiments.

AGCM experiments described in section 2. Figure 2 presents the simulated monthly-mean precipitation anomalies from May to August obtained in the TA, IP and GT experiments. In TA, the response of WA precipitation to a warming in the tropical Atlantic (Figures 2a-2d) has a dipolar pattern, with positive rainfall anomalies over the Gulf of Guinea and negative ones to the north reaching $15 \mathrm{~N}$. Magnitudes of rainfall anomalies are larger in spring (May-June), when SST anomalies are strong. In IP, the precipitation response to a cooling of the eastern Pacific (Figures 2e-2h) shows the northward displacement of enhanced precipitation from the Gulf of Guinea to the Sahel as the season advances. Finally, in GT, precipitation anomalies of (Figures $2 \mathrm{j}-2 \mathrm{l}$ ) resemble the observations (Figure A4 in Text S1), with a dipolar structure in May and June that becomes a monopolar pattern during the monsoon season (July-August).

[14] The dynamical mechanisms at work in the TA experiment include changes in the large-scale circulation induced by the reduction of the zonal gradient of surface pressure by the tropical Atlantic warming (not shown), consistent with previous works [Losada et al., 2010a; Bader and Latif, 2011].

[15] To examine the upper level circulation associated with the SST anomalies in the Indo-Pacific region we look at the eddy-streamfunction field at $200 \mathrm{hPa}$, where by "eddy" we mean deviation from the zonal mean (Figures $3 a$ and $3 b$ ). The results show a Gill-Matsuno type response to equatorial diabatic cooling in the Pacific, with a pair of anomalous cyclones straddling the equator [Gill, 1980]. Also, two pairs of anomalous anticyclones appear at both sides of the equator in the Indian and Atlantic Oceans. The former is consistent with an equatorial Rossby wave response to the warming over the Indian Ocean; the latter pair is also consistent with an anomalous tropospheric warming associated with increased convection over the tropical Atlantic due to the modification of the Walker circulation by the cooling in the eastern Pacific.

[16] In May (Figure 3a) and June (not shown) the anomalous anticyclones cover the whole Atlantic basin and the anomalous ascending motions (not shown) are consistent with the increase of precipitation in the equatorial Atlantic and Gulf of Guinea and the decrease to the north of those regions (Figures $2 \mathrm{e}$ and $2 \mathrm{f}$ ).

[17] During July (not shown) and August (Figure 3b), the intensification of the warming over the Maritime Continent enhances the anomalous upper level anticyclone over India. This warming affects the circulation over the African continent, producing anomalous downward motion and upper level convergence over equatorial Africa, anomalous upper level divergence over the Sahel (not shown), and the anomalous precipitation pattern in Figures $2 \mathrm{~g}$ and $2 \mathrm{~h}$. These results resemble those obtained by Mohino et al. [2011a].

[18] Results of the GT experiment are shown in terms of the monthly-mean anomalous eddy-streamfunction (Figures 3c and 3d) and divergence at $200 \mathrm{hPa}$ (Figure 4). In May (Figure 3c) and June (not shown), the eddy-streamfunction pattern is very similar to the one in IP, although the anomalous circulation over the Atlantic is stronger and that over the Indian sector is weaker. This is consistent with the large-scale effect of the tropical Atlantic warming, which produces a Gill-Matsuno type response with anomalous subsidence over the Indian sector [Kucharski et al., 2009; Losada et al., 2010b]. In the GT experiment, this effect of the tropical 


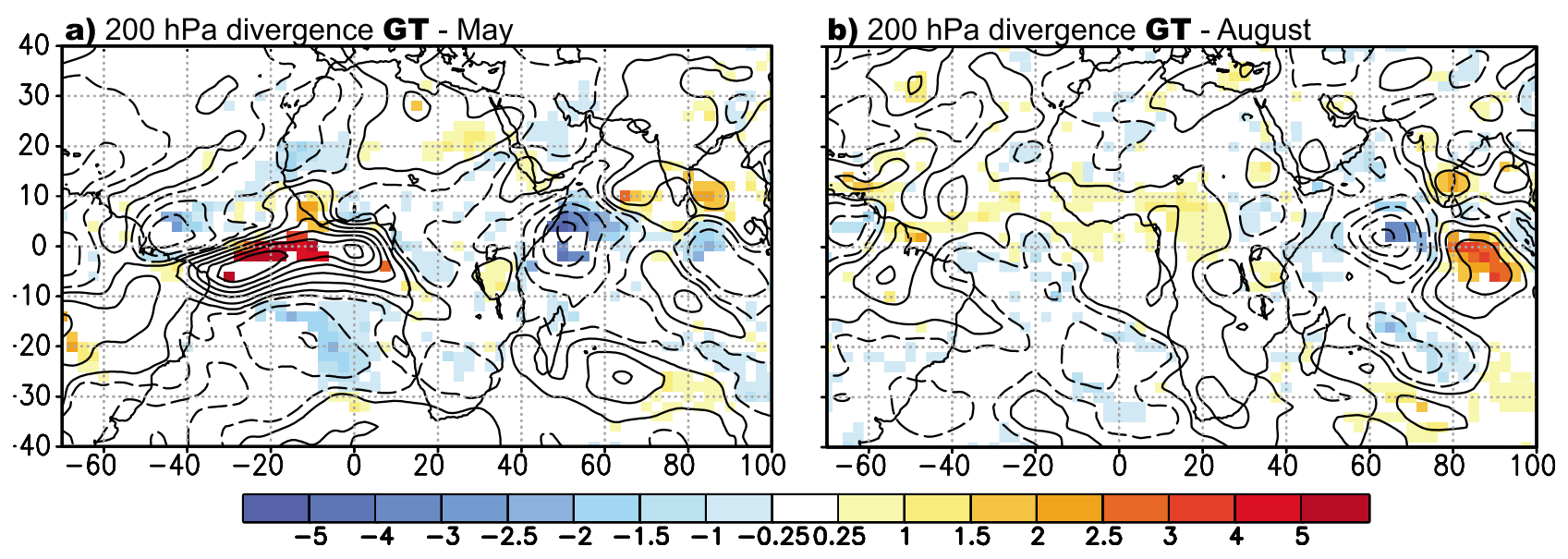

Figure 4. (a) May and (b) August $200 \mathrm{hPa}$ divergence $\left(\mathrm{s}^{-1}\right)$ for GT experiment. Shading denotes the regions where the ratio mean-standard deviation of both models is larger than one; solid (dashed) lines denote positive (negative) anomalies.

Atlantic counteracts the Gill response to the warming of the Maritime Continent, leading to the weakening of the anomalous anticyclone there. During May and June, the SST anomalies in the Atlantic and Indo-Pacific have a similar impact on West African precipitation when acting separately (Figures 2a, 2b, 2e and 2f). Thus, one would expect those anomalies to interact constructively in terms of anomalous precipitation in May and June; a feature that is confirmed comparing Figures $2 \mathrm{i}$ and $2 \mathrm{j}$ (GT precipitation) with Figures $2 \mathrm{~m}$ and $2 \mathrm{n}$ (sum of precipitation obtained in TA and IP).

[19] In July (not shown) and August (Figure 4b), the warm Atlantic SSTs continue enhancing the local upper level divergence and weakening the upper level anticyclone and the $200 \mathrm{hPa}$ divergence over the Indian sector (Figure 3d). The effects of SST anomalies in the Atlantic on the largescale circulation are opposite to those in the Pacific. Therefore, the combined action of these SST anomalies should discourage the presence of the maximum anomalous upper level convergence over equatorial Africa that was present in the IP simulations. Considering this anomalous pattern in the upper troposphere in the GT simulation, the upper level divergence (Figure $4 \mathrm{~b}$ ) produces the enhancement of the precipitation over the Gulf of Guinea and Sahel during August.

[20] One of the most important results obtained in this study is that the anomalous circulation patterns in the GT experiment broadly correspond to the sum of those in TA and IP (Figures $2 \mathrm{~m} \mathrm{2p}, 3 \mathrm{e}$, and $3 \mathrm{f}$ ). Therefore, the atmospheric response to the SST anomalies in the different oceans basins is mostly linear. In May and June, the Atlantic warming and the Pacific cooling add their effects in the Equatorial Atlantic, increasing the surface convergence and resulting in the anomalous rainfall dipole in WA. From July on, the SST anomalies of the Equatorial Atlantic weaken greatly, leading to the weakening of the anomalous rainfall dipole. During this month, the influence of the Indian and western Pacific SST over the Sahel strengthens, enhancing the upper level divergence over this region that was already present due to the compensating warming to the cooling in the eastern Pacific [Rowell, 2001]. This enhanced divergence prevails over the effect of the Atlantic, leading to the disappearance of the anomalous rainfall dipole and favoring the development of a monopolar rainfall pattern over WA in August.

\section{Summary and Conclusions}

[21] We have presented the seasonal evolution of an SST anomalous pattern over the global tropics that appears after the 1970's in correlation with anomalies in WA rainfall. In this period, SST anomalies in the tropical Atlantic appear in combination with others in the Indian and Pacific oceans. Such a combination does not hold before the 1970's, which gives rise to the non-stationary character of the links between WA rainfall and tropical SST anomalies.

[22] Next we demonstrated, based on AGCM ensemble integrations, that prescribed SST anomalies corresponding to the SST pattern either in the global tropics or in each of the tropical basins, produce significantly different anomalies in WA rainfall. Our AGCM-based study shows that the impact of the individual ocean basins on WA rainfall seems to be relatively stationary over time. The model experiment with SST anomalies in the tropical Atlantic only (TA), for example, clearly produces a rainfall dipole pattern in summer over WA. After the 1970's, when the SST anomalies in the Atlantic appear accompanied by anomalies in the IndoPacific, the constructive and destructive interferences among these SSTs during the northern warm season change the pattern of anomalous precipitation over WA. In spring (May-June) the impact of SST anomalies in the tropical Indo-Pacific on WA rainfall reinforces that of SST anomalies in the tropical Atlantic, leading to a well-defined precipitation dipole. By contrast, in summer (July-August) the influence of the SST anomalies in the Indo-Pacific over the Sahel is opposite to that of the SST anomalies in the tropical Atlantic. This counteracting effect and dominance of the anomalies in the Pacific drastically weakens the dipolar feature of WA precipitation when the tropical basins are considered simultaneously. The mechanisms at work for the impact are related to equatorial dynamics involving different Gill-Matsuno responses to anomalous diabatic cooling or heating in each of the tropical basins.

[23] These findings explain two important features observed in WA rainfall during the northern summer after1970's: 1) the lack of significant negative correlations 
between precipitation anomalies in the Gulf of Guinea and the Sahel [Polo et al., 2008; Joly and Voldoire, 2010]; and 2) the disappearance of precipitation anomalies with opposite sign over the Sahel and the Gulf of Guinea in response to tropical Atlantic SST anomalies. The results provide a quantitative confirmation of conjectures on the linearity of the impacts of tropical SST anomalies on WA rainfall raised in previous works [Joly et al., 2007; Joly and Voldoire, 2010; MO11; Rodríguez-Fonseca et al., 2011]. They also clarify the impact of ENSO on Sahel rainfall and thereby emphasize the need to consider the global climate system for successful seasonal forecasts.

[24] What causes such decadal changes in the interannual variability of the SST is an open subject that motivates a number of questions on the origin of the multidecadal modulation of the interannual patterns of SST and their influence on Sahelian rainfall. These topics will be addressed in future works.

[25] Acknowledgments. This project has been partially funded by the EU-AMMA project. Based on French initiative, AMMA was built by an international scientific group and is currently funded by a large number of agencies, especially from France, UK, US and Africa. It has been the beneficiary of a major financial contribution from the European Community's Sixth Framework Research Programme. Detailed information on scientific coordination and funding is available on the AMMA International website $\mathrm{http}: / /$ www.amma-international.org. This study has been also supported by the Spanish projects: MICINN CGL2009-10285, CGL2011-13564-E, MMA MOVAC-200800050084028 and the Research Group "Micrometeorology and Climate Variability". We would like to thank the EEA "Abel Extraordinary Chairs" for the mobility grant of Dr Rodriguez-Fonseca to the Bjerknes Center for Climate Research and the University of Bergen. The research at UCLA was funded by NSF grant AGS-1041477. T. Losada is supported by the postdoctoral program by the Consejería de Educación, Cultura y Deporte of the Junta de Comunidades de Castilla-La Mancha (Spain) and the European Social Found. The authors thank two anonymous reviewers for their constructive suggestions and comments that have improved the paper, as well as the editor for his help through the whole process of publication of the paper.

[26] The Editor thanks two anonymous reviewers for assisting in the evaluation of this paper.

\section{References}

Bader, J., and M. Latif (2011), The 1983 drought in the West Sahel: A case study, Clim. Dyn., 36, 463-472, doi:10.1007/s00382-009-0700-y.

Bretherton, S. B., C. Smith, and J. M. Wallace (1992), An intercomparison of methods for finding coupled patterns in climate data, J. Clim., 5, 541-560, doi:10.1175/1520-0442(1992)005<0541:AIOMFF>2.0.CO;2.

Folland, C. K., T. N. Palmer, and D. E. Parker (1986), Sahel rainfall and worldwide sea temperatures, 1901-85, Nature, 320, 602-607, doi: $10.1038 / 320602 \mathrm{a} 0$.

Fontaine, B., S. Trzaska, and S. Janicot (1998), Evolution of the relationship between near global and Atlantic SST modes and the rainy season in West Africa: Statistical analyses and sensitivity experiments, Clim. Dyn., 14, 353-368, doi:10.1007/s003820050228.

Giannini, A., R. Saravannan, and P. Chang (2003), Oceanic forcing of Sahel rainfall on interannual to interdecadal time scales, Science, 302, 1027-1030, doi:10.1126/science. 1089357.

Gill, A. E. (1980), Some simple solutions for heat-induced tropical circulation, Q. J. R. Meteorol. Soc., 106, 447-462, doi:10.1002/qj.49710644905.

Hourdin, F., et al. (2006), The LMDZ4 general circulation model: Climate performance and sensitivity to parametrized physics with emphasis on tropical convection, Clim. Dyn., 27, 787-813, doi:10.1007/s00382-0060158-0.

Janicot, S., A. Harzallah, B. Fontaine, and V. Moron (1998), West African monsoon dynamics and eastern equatorial Atlantic and Pacific SST anomalies (1970-1988), J. Clim., 11, 1874-1882, doi:10.1175/15200442-11.8.1874

Janicot, S., S. Trzaska, and I. Poccard (2001), Summer Sahel-ENSO teleconnection and decadal time scale SST variations, Clim. Dyn., 18, 303-320, doi: $10.1007 / \mathrm{s} 003820100172$.
Joly, M., and A. Voldoire (2010), Role of the Gulf of Guinea in the interannual variability of the West African monsoon: What do we learn from CMIP3 coupled simulations?, Int. J. Climatol., 30, 1843-1856, doi:10.1002/joc. 2026.

Joly, M., A. Voldoire, H. Douville, P. Terray, and J. F. Royer (2007), African monsoon teleconnections with tropical SSTs: Validation and evolution in a set of IPCC4 simulations, Clim. Dyn., 29, 1-20, doi:10.1007/s00382-006-0215-8.

Kucharski, F., A. Bracco, J. H. Yoo, A. Tompkins, L. Feudale, P. Ruti, and A. Dell'Aquila (2009), A Gill-Matsun-type mechanism explains the tropical Atlantic influence on African and Indian monsoon rainfall, $Q . J . R$. Meteorol. Soc., 135, 569-579, doi:10.1002/qj.406.

Losada, T., B. Rodriguez-Fonseca, S. Janicot, S. Gervois, F. Chauvin, and P. Ruti (2010a), A multimodel approach to the Atlantic equatorial mode: Impact on the West African monsoon, Clim. Dyn., 35, 29-43, doi:10.1007/s00382-009-0625-5.

Losada, T., B. Rodriguez-Fonseca, I. Polo, S. Janicot, S. Gervois, F. Chauvin, and P. Ruti (2010b), Tropical response to the Atlantic equatorial mode: AGCM multimodel approach, Clim. Dyn., 35, 45-52, doi:10.1007/s00382-009-0624-6.

Mechoso, C. R., J. Y. Yu, and A. Arakawa (2000), A coupled GCM pilgrimage: from climate catastrophe to ENSO simulations, in General Circulation Model Development: Past, Present and Future, Int. Geophys. Ser., vol. 70, edited by D. A. Randall, pp. 539-575, Academic, New York, doi:10.1016/S0074-6142(00)80066-2.

Meehl, G. A. et al. (2007), Global climate projections, in Climate Change 2007: The Physical Science Basis. Contribution of Working Group I to the Fourth Assessment Report of the Intergovernmental Panel on Climate Change, edited by S. Solomon et al., pp. 747-845, Cambridge Univ. Press, Cambridge, U. K.

Mohino, E., B. Rodríguez-Fonseca, C. R. Mechoso, S. Gervois, P. Ruti, and F. Chauvin (2011a), Impacts of the tropical Pacific/Indian Oceans on the seasonal cycle of the West African monsoon, J. Clim., 24, 3878-3891, doi:10.1175/2011JCLI3988.1.

Mohino, E., B. Rodríguez-Fonseca, T. Losada, S. Gervois, S. Janicot, J. Bader, P. Ruti, and F. Chauvin (2011b), SST-forced signals on West African rainfall from AGCM simulations-Part I: Changes in the interannual modes and model intercomparison, Clim. Dyn., 37, 1707-1725, doi:10.1007/s00382-011-1093-2.

Polo, I., B. Rodríguez-Fonseca, T. Losada, and J. García-Serrano (2008), Tropical Atlantic variability modes (1979-2002). Part I: Time-evolving SST modes related to West African rainfall, J. Clim., 21, 6457-6475, doi:10.1175/2008JCLI2607.1.

Richter, I., C. R. Mechoso, and A. W. Robertson (2008), What determines the position and intensity of the South Atlantic anticyclone in austral winter? An AGCM study, J. Clim., 21, 214-229, doi:10.1175/ 2007JCLI1802.1.

Rodríguez-Fonseca, B., I. Polo, J. García-Serrano, T. Losada, E. Mohino, C. R. Mechoso, and F. Kucharski (2009), Are Atlantic Niños enhancing Pacific ENSO events in recent decades?, Geophys. Res. Lett., 36, L20705, doi:10.1029/2009GL040048.

Rodríguez-Fonseca, B., et al. (2011), Interannual and decadal SST forced responses of the West African monsoon, Atmos. Sci. Lett., 12, 67-74, doi:10.1002/asl.308.

Rowell, D. P. (2001), Teleconnections between the tropical Pacific and the Sahel, Q. J. R. Meteorol. Soc., 127, 1683-1706, doi:10.1002/ qj. 49712757512 .

Rowell, D. P., C. K. Folland, K. Maskel, J. A. Owen, and M. N. Ward (1995), Variability of the summer rainfall over tropical North Africa (1906-92): Observations and modeling, Q. J. R. Meteorol. Soc., 121, 669-704, doi:10.1002/qj.49712152311

Smith, T. M., and R. W. Reynolds (2004), Improved extended reconstruction of SST (1854-1997), J. Clim., 17, 2466-2477, doi:10.1175/15200442(2004)017<2466:IEROS>2.0.CO;2.

Trzaska, S., V. Moron, and B. Fontaine (1996), Global atmospheric response to specific linear combinations of the main SST modes. Part I: Numerical experiments and preliminary results, Ann. Geophys., 14, 1066-1077.

Ward, M. N. (1998), Diagnosis and short-lead time prediction of summer rainfall in tropical North Africa at interannual and multidecadal timescales, J. Clim., 11, 3167-3191, doi:10.1175/1520-0442(1998) $011<3167$ :DASLTP $>2.0 . \mathrm{CO} ; 2$.

Xie, P., and P. A. Arkin (1997), Global precipitation: A 17-year monthly analysis based on gauge observations, satellite estimates, and numerical model outputs, Bull. Am. Meteorol. Soc., 78, 2539-2558, doi:10.1175/ 1520-0477(1997)078<2539:GPAYMA $>2.0 . C O ; 2$. 